\title{
Mucor Rot-An Emerging Postharvest Disease of Mandarin Fruit Caused by Mucor piriformis and other Mucor spp. in California
}

S. Saito, United States Department of Agriculture-Agricultural Research Service (USDA-ARS), San Joaquin Valley Agricultural Sciences Center, Parlier, CA 93648; T. J. Michailides, University of California, Kearney Agricultural Research and Extension Center, Parlier 93648; and C. L. Xiao, USDA-ARS, San Joaquin Valley Agricultural Sciences Center

\begin{abstract}
Saito, S., Michailides, T. J., and Xiao, C. L. 2016. Mucor rot—An emerging postharvest disease of mandarin fruit caused by Mucor piriformis and other Mucor spp. in California. Plant Dis. 100:1054-1063.

In recent years, an emerging, undescribed postharvest disease was observed on mandarin fruit after extended storage in California. We collected decayed mandarin fruit from three citrus packinghouses in the Central Valley of California in 2015 and identified this disease as Mucor rot caused by Mucor spp. Mucor rot occurred in 11 of the 15 grower lots sampled, and the percentage of Mucor rot in the total decayed fruit varied among affected grower lots, ranging from 3.3 to $93.1 \%$ with an average of $49.2 \%$. In total, 197 isolates of Mucor spp. were obtained from decayed mandarin fruit and identified based on internal transcribed spacer sequence and morphological characteristics. Of the 197 isolates, $182(92.4 \%)$ were identified as Mucor piriformis, 7 (3.6\%) were M. circinelloides (6 M. circinelloides $\mathrm{f}$. lusitanicus and $1 \mathrm{M}$. circinelloides f. circinelloides), 4 (2\%) were $M$. racemosus f. racemosus, $3(1.5 \%)$ were $M$. hiemalis, and $1(0.5 \%)$ was $M$. mucedo. All species grew at 0 and $5^{\circ} \mathrm{C}$, except $M$. circinelloides, which did not grow at $0^{\circ} \mathrm{C}$. Mycelial growth was arrested at $27^{\circ} \mathrm{C}$ for M. piriformis; $35^{\circ} \mathrm{C}$ for $M$. racemosus f. racemosus, M. circinelloides f. lusitanicus, M. hiemalis and M. mucedo; and $37^{\circ} \mathrm{C}$ for M. circinelloides

f. circinelloides. Optimal mycelial growth occurred at $20^{\circ} \mathrm{C}$ for M. piriformis and M. mucedo, $25^{\circ} \mathrm{C}$ for M. racemosus f. racemosus and M. hiemalis, $27^{\circ} \mathrm{C}$ for M. circinelloides f. lusitanicus, and $30^{\circ} \mathrm{C}$ for $M$. circinelloides f. circinelloides. M. piriformis grew significantly faster than the other four species at 5 and $20^{\circ} \mathrm{C}$, and $M$. mucedo was the slowest in growth among the five species. Sporangiospores of $M$. piriformis, M. racemosus f. racemosus, and M. hiemalis germinated at both 5 and $20^{\circ} \mathrm{C}$. M. circinelloides germinated at $20^{\circ} \mathrm{C}$ but did not germinate at $5^{\circ} \mathrm{C}$ after incubation for $48 \mathrm{~h}$. All five Mucor spp. caused decay on mandarin fruit inoculated with the fungi, and the lesion size caused by $M$. piriformis was significantly larger than that caused by other species at both 5 and $20^{\circ} \mathrm{C}$. Our results indicated that Mucor rot in mandarin fruit in California is caused by Mucor spp. consisting of $M$. piriformis, M. circinelloides, M. racemosus f. racemosus, M. hiemalis, and M. mucedo, with $M$. piriformis being the dominant and most virulent species. Previously, $M$. racemosus was reported on citrus. This is the first report of Mucor rot in citrus caused by M. piriformis, M. circinelloides, M. hiemalis, and M. mucedo.
\end{abstract}

Citrus is one of the most important fruit crops in the world and has grown commercially in more than 140 countries located in tropical and subtropical areas (Terol et al. 2007). In the United States, California is the leading producer of fresh-market citrus, accounting for about $76 \%$ of the production in 2013 (CDFA-CASS 2014). Among various types of citrus produced in the region, California leads in navel orange production and also produces significant percentages of the nation's Valencia orange, lemon, and grapefruit. However, during the last decade, there has been a constant decrease in consumption of "difficult-to-peel" citrus fruit such as orange and grapefruit, accompanied by increasing consumption and demand for "easy-topeel" mandarin fruit (Ladaniya 2008; USDA-FAS 2016). The biggest change in California's citrus industry in the past decade has been the increasing production of mandarin (Webber et al. 2014). The total acreage of orange orchards decreased from 75,700 to 68,400 ha from 2004 to 2014, while that of mandarin has steadily increased from

Corresponding author: C. L. Xiao; E-mail: Chang-Lin.Xiao@ars.usda.gov

Mention of trade names or commercial products in this article is solely for the purpose of providing specific information and does not imply recommendations or endorsement by the United States Department of Agriculture. USDA is an equal opportunity provider and employer.

*The $\boldsymbol{e}$-Xtra logo stands for "electronic extra" and indicates that one supplementary table is published online.

Accepted for publication 26 January 2016.

http://dx.doi.org/10.1094/PDIS-10-15-1173-RE

This article is in the public domain and not copyrightable. It may be freely reprinted with customary crediting of the source. The American Phytopathological Society, 2016.
7,200 to 18,600 ha in this period (CDFA-CASS 2014), with a production value in 2014 exceeding $\$ 500$ million (USDA-NASS 2015). Most mandarin fruit are marketed fresh and fill the harvest niche between Valencia orange and other summer fruit.

In California, at harvest, mandarin fruit are hand-picked and placed into plastic bins, which are then transported to packinghouses. Traditionally, mandarin fruit are presorted and packed into cartons or bags for marketing shortly after harvest. As the acreage of mandarin continues to expand, the industry has been exploring ways to expand the current marketing window. One such approach is to store mandarin fruit in a cold facility after harvest for a certain period of time and pack them at a later time. However, extended storage of fruit after presorting may predispose the fruit to the development of fruit rots because all types of citrus fruit are susceptible to postharvest fruit rots. Postharvest fruit rots caused by various fungal pathogens contribute to the most significant losses to the citrus industry during degreening, storage, transportation, and marketing (Akhtar et al. 2013; Smilanick et al. 2006).

Several postharvest fruit rots commonly affect citrus (Snowdon 1990). Postharvest diseases of citrus fruit can result from three types of infections: infections that develop during the growing season and continue to cause postharvest problems, infections that initiate in the field but remain latent before harvest and become active to develop decay symptoms only after harvest, and infections that initiate at wounds during harvest and postharvest handling (Arpaia et al. 2014). Green mold caused by Penicillium digitatum (Pers.) Sacc., blue mold caused by $P$. italicum Wehmer, and sour rot caused by Geotrichum citri-aurantii (Ferraris) E. E. Butler are generally considered the most common postharvest diseases in citrus worldwide (Akhtar et al. 2013; Bhattarai et al. 2013; McKay et al. 2012; Smilanick and Mansour 2007; Smilanick et al. 2006). However, the occurrence of postharvest fruit rots of citrus can be affected by both fruit growing conditions in the field and postharvest storage and handling practices (Arpaia et al. 2014; Smilanick et al. 2008). Citrus types and cultivars 
may exhibit varying susceptibility to different postharvest diseases. Although numerous studies on postharvest diseases of citrus have been documented, most of the research was conducted on orange and lemon and little research has been conducted regarding the postharvest fungal diseases of mandarin fruit in California.

In 2013, some citrus packinghouses in the Central Valley of California, which is a major region for citrus production, indicated that, in recent years, they had experienced an unknown postharvest disease on mandarin fruit, particularly on the fruit that had been stored for an extended period of time after harvest at low temperatures. During the 2014-15 storage season, we collected decayed mandarin fruit from three commercial citrus packinghouses in the region and confirmed that the unknown disease was caused by Mucor spp. Thus, the objectives of this study were to (i) describe Mucor rot on mandarin fruit caused by Mucor spp., (ii) identify Mucor spp. associated with fruit rot of mandarin in California, (iii) conduct comparative studies on the biology of different Mucor spp. associated with mandarin, and (iv) test pathogenicity of Mucor spp. on mandarin fruit.

\section{Materials and Methods}

Symptoms and occurrence of Mucor rot. Surveys for Mucor rot in stored mandarin fruit were conducted in the Central Valley of California during mid-January to the end of April in 2015. Decayed mandarin fruit were sampled from three packinghouses. At each sampling time, approximately 30 to 60 decayed fruit from one grower lot (one grower lot represents the fruit from the same orchard block) were arbitrarily sampled from storage bins in the packinghouses, and two to three grower lots were sampled each week. In total, 553 decayed fruit from 15 grower lots were sampled. Decayed fruit were placed individually on citrus fruit-packing trays and transported to the laboratory on the same day they were sampled. Samples were sorted by symptoms and the presence of wounds. Color and texture (firm, soft, or watery) of the decayed area were also recorded. All decayed fruit were photographed before pathogen isolation in order to correlate causal agents with the disease symptoms they incited.

Isolation and identification of causal agents. Identification of fungal pathogens was initially made based on disease symptoms exhibited on the rind of decayed fruit, and morphology of fungi under a microscope if sporulation or fruiting bodies of the pathogens were present on the fruit. All decayed fruit with sporulation similar to Mucor spp. were subjected to isolation of causal agents. To isolate causal agents from decayed fruit, decayed fruit were surface sterilized by spraying them with $70 \%$ ethanol and allowed to air dry in a fume hood. Small fragments of the rind were removed using a sterile scalpel from the margin of decayed and healthy tissue and placed onto petri dishes containing water agar. The plates were incubated at $20^{\circ} \mathrm{C}$ for 5 to 7 days, allowing fungal pathogens to grow. Mycelia actively growing on the edge of the colonies on the water agar were transferred onto potato dextrose agar (PDA; Difco Laboratories, Detroit). The PDA plates were then incubated at $20^{\circ} \mathrm{C}$ for another 4 to 5 days. Initial identification of putative Mucor isolates to the genus level was based on the descriptions of Schipper (1973, 1975, 1976, 1978). In total, 197 putative Mucor isolates were obtained from decayed mandarin fruit.

After the preliminary morphological analysis, single-sporangiospore isolation was conducted for all Mucor isolates. Sporangiospores from 1-week-old PDA cultures were scraped off using a sterile scalpel and suspended in $1 \mathrm{ml}$ of sterile distilled water with $0.1 \%$ of Tween 20 . An aliquot of $50 \mu \mathrm{l}$ of sporangiospore suspension was spread on water agar in a petri dish. After incubation at $20^{\circ} \mathrm{C}$ for 1 to 2 days, single germinated sporangiospores were transferred onto new PDA plates and incubated at $20^{\circ} \mathrm{C}$ for another 4 to 5 days for mycelial development. Mycelial plugs excised using a sterile scalpel were transferred into a 2-ml vial filled with $15 \%$ glycerol and stored at $-80^{\circ} \mathrm{C}$.

DNA extraction, polymerase chain reaction amplification, and sequencing of Mucor spp. All Mucor isolates were subjected to DNA sequencing for identification to the species level (Walther et al. 2013). Genomic DNA was extracted from mycelium of Mucor isolates grown on PDA using DNeasy Mini Spin Columns (Qiagen, Valencia, CA) according to the manufacturer's protocol. Resulting DNA solutions were used for sequencing as described below.
The internal transcribed spacer (ITS) region was amplified for all Mucor isolates using the primer pair ITS1/ITS4 (White et al. 1990). Polymerase chain reaction (PCR) was performed as described previously, with modifications (White et al. 1990). Briefly, PCR amplifications were performed in a $10-\mu l$ volume containing $10 \mathrm{ng}$ of fungal genomic DNA, $0.2 \mu \mathrm{M}$ each primer, and $5.0 \mu \mathrm{l}$ of GoTaq PCR mixture (Promega Corp., Madison, WI). PCR was carried out in a $\$ 1000$ thermal cycler (Bio-Lad Life Science Research Group, Hercules, CA) with the following conditions: an initial preheating for $2 \mathrm{~min}$ at $95^{\circ} \mathrm{C}$; followed by 30 cycles of denaturation at $95^{\circ} \mathrm{C}$ for $30 \mathrm{~s}$, annealing at $55^{\circ} \mathrm{C}$ for $30 \mathrm{~s}$, and extension at $72^{\circ} \mathrm{C}$ for $1 \mathrm{~min}$; and a final extension at $72^{\circ} \mathrm{C}$ for $5 \mathrm{~min}$.

PCR products were purified using a GeneJet purification kit (Thermo Fisher Scientific, Pittsburgh) according to manufacturer's protocols. Purified PCR products were then directly sequenced in both directions using BigDye Terminator v3.1 Cycle Sequencing Kit in a 3130XL Genetic Analyzer (Applied Biosystems, Inc., Foster City, CA). Sequences were analyzed using BioEdit Sequence Alignment Editor, v7.1.11 (Hall 1999). The ITS sequences of the 197 Mucor isolates from mandarin fruit were subjected to a Mega BLAST search on the National Center for Biotechnology (NCBI) website (http://www.ncbi.nlm.nih.gov/) to find highly similar sequence data, and then were compared with the sequences of extype strains of the known Mucor spp. reported previously (Walther et al. 2013).

Morphological characteristics. Two isolates each of Mucor piriformis (X1816 and X1944), M. racemosus f. racemosus (X1650 and X2081), and M. hiemalis (X1946 and X2121); three isolates of M. circinelloides (X1785, X1899, and X1935); and one isolate of M. mucedo (X2142) that were identified by ITS sequencing were selected for morphological characterization. To compare morphological characteristics of Mucor spp. from mandarin fruit with the known taxa of Mucor spp., all isolates were cultured on PDA and beer wort agar (BWA) following the procedure of Schipper (1973, 1975, 1976, 1978). For all isolates, 1-week-old cultures incubated at $20^{\circ} \mathrm{C}$ in darkness were used for measuring the dimensions of sporangiospores, sporangia, and columellae. Averages or size ranges of the measurements for each organ were calculated from at least 50 measurements for each isolate. Experiments were performed twice. Morphological characteristics on BWA were observed daily, recorded, and compared with the morphological descriptions of the known Mucor spp. (Schipper 1973, 1975, 1976, 1978).

In addition, to compare potential differences in culture morphology, one representative isolate each of four Mucor spp.-X1816 (M. piriformis), X1650 (M. racemosus f. racemosus), X2121 (M. hiemalis), and X2142 (M. mucedo)—and two isolates of M. circinelloides-X1785 (M. circinelloides f. lusitanicus) and X1899 (M. circinelloides f. circinelloides)—were cultured on four different media: (i) PDA, (ii) BWA (Schipper 1973, 1975, 1976, 1978), (iii) synthetic Mucor agar (SMA) (Michailides 1991), and (iv) orange juice agar (OJA). OJA was made based on apple juice agar (Xiao and Sitton 2004) by substituting apple juice with orange juice. The ingredients of OJA were as follows: $200 \mathrm{ml}$ of orange juice (Sunnyside Farms, Turlock, CA), $3.0 \mathrm{~g}$ of $\mathrm{CaCO}_{3}, 15 \mathrm{~g}$ of agar, and $800 \mathrm{ml}$ of deionized water.

Agar plugs $(5 \mathrm{~mm})$ containing actively growing mycelium were excised with a sterile cork borer from the edge of 2- to 3-day-old SMA cultures at $20^{\circ} \mathrm{C}$, and one such mycelial plug was placed upside-down in the center of each plate. Three replicate plates of each medium were used for each isolate. Colony diameter was measured in two perpendicular directions after $48 \mathrm{~h}$ of incubation at $20^{\circ} \mathrm{C}$ in the dark and means were calculated after subtracting the diameter of the original plug $(5 \mathrm{~mm})$. Each plate was photographed at the end of the experiments. Experiments were performed twice.

Mycelial growth in response to temperature. Radial mycelial growth of Mucor spp. at different temperatures was determined on SMA in 90-mm petri dishes (Michailides 1991), with slight modifications. Briefly, an agar plug (5 $\mathrm{mm}$ in diameter) containing actively growing mycelium prepared as described above was placed upsidedown in the center of a new SMA plate. Two isolates each of 
M. piriformis, $M$. racemosus f. racemosus, and M. hiemalis; seven isolates of $M$. circinelloides ( $\operatorname{six} M$. circinelloides f. lusitanicus and one $M$. circinelloides f. circinelloides); and one isolate of $M$. mucedo were used for this test. Three replicate plates were used for each isolate. The plates were incubated in the dark at 0, 5, 10, 15, 20, 25, 27, $30,35,37$, and $40^{\circ} \mathrm{C}$. The colony diameter in each plate was measured as described above after 24 and $48 \mathrm{~h}$ of incubation for all temperatures except $0^{\circ} \mathrm{C}$. Because all Mucor isolates grew slowly at $0^{\circ} \mathrm{C}$, the colony diameter was measured after 3 and 6 days for isolates X1816 and X1944 (M. piriformis) and 1 and 2 weeks for the isolates of other species. Radial mycelial growth rate of each isolate was then calculated and expressed as millimeters per day. Experiments were performed twice.

Germination of sporangiospores. To determine germination of sporangiospores, a $50-\mu 1$ aliquot of the sporangiospore suspension of each isolate, prepared as described above, was pipetted onto a 90-mm petri dish containing SMA and spread evenly on the surface. Three replicate plates for each isolate were incubated in the dark at $5^{\circ} \mathrm{C}$ for $48 \mathrm{~h}$ or at $20^{\circ} \mathrm{C}$ for $14 \mathrm{~h}$. Because isolate X2142 (M. mucedo) did not germinate on SMA after respective incubation conditions, germination was then tested on OJA following the same procedure. At the end of the incubation period, at least 100 sporangiospores in each plate were examined under a microscope $(\times 10)$ and the average percentage of germination of sporangiospores was calculated for each isolate at each temperature. Experiments were performed twice.

Pathogenicity tests. Two isolates each of M. piriformis (X1816 and X1944) and M. circinelloides (X1785 [M. circinelloides f. lusitanicus] and X1899 [M. circinelloides f. circinelloides]) and one isolate each of M. racemosus f. racemosus (X1650), M. hiemalis (X2121), and M. mucedo (X2192) were used in this study.

To make the sporangiospore suspension, 1- to 2-week-old PDA cultures of the isolates that were incubated at $20^{\circ} \mathrm{C}$ in the dark were flooded with sterile distilled water and scraped with a sterile rod, and the resultant sporangiospore suspension was filtered through autoclaved gauze. Number of sporangiospores in the suspension was estimated under a microscope with the aid of a hemocytometer and diluted to a concentration of $1.0 \times 10^{5}$ sporangiospores $/ \mathrm{ml}$.

Mandarin fruit ('W. Murcott') that were not treated with any postharvest treatments and provided by a local packinghouse were used for pathogenicity tests. Prior to the experiments, fruit were surface sterilized by dipping them into $0.5 \%$ sodium hypochlorite for 2 min, rinsed with sterile water three times, and allowed to air dry in a fume hood. The fruit were then placed individually on the base of 35-mm petri dishes so that each fruit was held steady for inoculation. Two different inoculation methods were used in this study.

Wound inoculation. A wound $(3 \mathrm{~mm}$ in diameter and $7 \mathrm{~mm}$ in depth) was made approximately $1.5 \mathrm{~cm}$ away from the stem end of the fruit using a sterile needle inserted into the rind. An aliquot of $10 \mu \mathrm{l}$ of the sporangiospore suspension of the isolate was pipetted into each wound. Ten fruit were used for each isolate. The fruit treated with sterile water were used as noninoculated controls. After inoculation, the inoculated fruit held on the base of petri dishes were then placed into clear plastic containers, which were then covered. Paper towels saturated with sterile distilled water were placed on the bottom of the containers to establish high relative humidity in the containers, and the containers were incubated in the dark at $5^{\circ} \mathrm{C}$ for 3 weeks or at $20^{\circ} \mathrm{C}$ for 11 days. After incubation, disease symptoms on the fruit were recorded. All fruit were then cut vertically in half, passing through the wound, using a sterile cutter, and the disease symptoms inside of the fruit were also recorded. At the end of the experiment, three decayed fruit inoculated with each isolate were arbitrarily chosen in attempts to reisolate the pathogen. Single-sporangiospore isolation was conducted for each recovered fungus, followed by morphological identification and DNA sequencing for speciation as described above, to fulfill Koch's postulates. Experiments were performed twice.

Cut-fruit inoculation. Preliminary experiments indicated that decay lesions developed on wound-inoculated fruit were often irregular on the rind of the fruit, making lesion size measurement to quantify the differences in virulence among Mucor spp. difficult. Thus, we used the cut-fruit assay as described below to quantify the potential differences in virulence among the isolates of Mucor spp. tested in this study.

Approximately one-third of each fruit was sliced off vertically in the direction from the stem end to the stylar end of the fruit using a sterile cutter. Each cut fruit was placed with the cut-side up on the base of a 35-mm petri dish in order to hold the fruit steady. An aliquot of $5 \mu \mathrm{l}$ of the sporangiospore suspension of an isolate was placed at the center of the cut surface of the cut fruit using a micropipette. Ten replicate fruit were used for each isolate. The fruit treated with sterile water were used as noninoculated controls. After inoculation, the fruit were transferred into plastic containers with the same conditions as described above. The containers were incubated in the dark at $5^{\circ} \mathrm{C}$ for 9 days and at $20^{\circ} \mathrm{C}$ for 2 days. The fruit inoculated with isolate X1899 (M. circinelloides f. circinelloides) showed no or very small decay lesions 9 days after inoculation at $5^{\circ} \mathrm{C}$; therefore, an additional 10-day incubation time was added for these fruit and, thus, the result of isolate X1899 was excluded from the statistical analysis described below. On the cut fruit, Mucor rot developed circular lesions. At the end of incubation, the presence of Mucor rot symptoms on each fruit was recorded, and lesion size on the cut surface was measured for each fruit. Experiments were performed twice.

Statistical analysis. All statistical analyses were conducted using SAS (version 9.4; SAS Institute, Inc., Cary, NC). The percentage data from the germination tests were arcsine-square root transformed prior to analysis. Analysis of variance using PROC GLM in SAS was performed to determine if data across the runs of each experiment could be pooled. The test indicated that there were no interactions between run and variables $(P>0.05)$, and thus all data were pooled and further analyzed using PROC GLM, and mean separations were made by Tukey's honestly significant difference multirange tests.

\section{Results}

Symptoms, prevalence, and incidence of the disease. On decayed fruit collected from packinghouses, Mucor rot appeared to develop from infections through puncture wounds or cracks on the rind of the fruit (Fig. 1). In the early stage of symptom development, lesions were quasicircular or irregular, light to dark brown, and soft and watery, and sporangiophores of Mucor spp. protruded from the wounds or cracks (Fig. 1). At the advanced stage of disease development, infected fruit generally were completely covered with masses of white or white to gray shiny, erect sporangiophores, on the top of which black or pale brown sporangia were evident, and decayed tissues were very watery (Fig. 1). Mucor rot symptoms were also observed on decayed fruit intermixed with sporulation of other decay pathogens such as Penicillium or Geotrichum spp.

Mucor rot was observed in fruit sampled from all three packinghouses. Mucor rot occurred in 11 of the 15 grower lots sampled, and the percentage of Mucor rot in the total decayed fruit varied greatly among affected grower lots, ranging from 3.3 to $93.1 \%$, with an average of $49.2 \%$ (Table 1). On average, Mucor rot accounted for $1.7,52.0$, and $54.6 \%$ of the decayed fruit for the samples collected from packinghouses I, II, and III, respectively (Table 1).

Mucor spp. identified by ITS sequencing. Based on the ITS sequences of the 197 Mucor isolates, the Mega BLAST search on NCBI (http://www.ncbi.nlm.nih.gov/) showed that 182 (92.4\%), $4(2 \%), 3(1.5 \%)$, and 1 isolate $(0.5 \%)$ had ITS sequences with high similarities to those of ex-type strains of $M$. piriformis (accession number JN206028; >97\%), M. racemosus f. racemosus (accession number JN205898; >99\%), M. hiemalis (accession number JN206129; >99\%), and M. mucedo (accession number JN206085; $>96 \%$ ), respectively; thus, they were identified as $M$. piriformis, M. racemosus f. racemosus, $M$. hiemalis, and $M$. mucedo, respectively. Six isolates (X1785, X1935, X1945, X1949, X2158, and X2159) had ITS sequences with $97 \%$ similarity to that of $M$. circinelloides f. lusitanicus (accession number JN205980), and one isolate (X1899) had 98\% similarity in ITS sequence to that of $M$. circinelloides $\mathrm{f}$. circinelloides (accession number JN205942). GenBank accession numbers for sequences of representative isolates of the five species of Mucor from mandarin fruit are listed in Supplementary Table S1. 
Morphological characteristics. Schipper (1973, 1975, 1976, 1978) described morphological characteristics of Mucor spp. based on the cultures on BWA incubated at $20^{\circ} \mathrm{C}$ in the dark; therefore, in the present study, all observations of morphological characteristics of the five Mucor spp. identified by ITS sequencing were made under the same conditions (Table 2; Fig. 2).

Isolates X1816 and X1944, identified as M. piriformis based on ITS sequences, had a colony up to $45 \mathrm{~mm}$ in height, white, and aromatic; sporangiophores bore droplets at the basal part, unbranched at first, then branched with short branches; sporangia were blackish and variable in size, ranging from 78 to 249 by 81 to $279 \mu \mathrm{m}$; columellae variable in shape and size, the large columellae obovoid or pyriform, the smaller columellae cylindrical-ellipsodial or pyriform, ranging from 45 to 186 by 75 to $207 \mu \mathrm{m}$; sporangiospores ellipsoidal or subglobose to globose, 4.7 to 10.9 by 3.0 to $9.5 \mu \mathrm{m}$. These morphological characteristics were in agreement with the descriptions of M. piriformis (Schipper 1975).

Isolates X1650 and X2081, identified as M. racemosus f. racemosus based on ITS sequences, had a colony up to $20 \mathrm{~mm}$ in height, white to grayish; sporangiophores branched in a mixed sympodial and monopodial fashion, sporangia pale brown to pale gray, variable in size, ranging from 25 to 90 by 25 to $89 \mu \mathrm{m}$; columellae variable in shape and size, obovoid, ellipsoidal, cylindrical-ellipsodial to subglobose or pyriform, usually with truncate base, ranging from 14 to 55 by 14 to $43 \mu \mathrm{m}$; sporangiospores ellipsoidal to subglobose, 4.3 to 10.1 by 3.5 to $7.9 \mu \mathrm{m}$, clamydospores numerous in sporangiospores and even in a few columellae. These morphological characteristics were in agreement with the descriptions of $M$. racemosus f. racemosus (Schipper 1976).

Isolates X1785 and X1935, identified as M. circinelloides f. lusitanicus based on ITS sequences, had a colony up to $4 \mathrm{~mm}$ in height, white to pale gray; sporangiophores repeatedly branched sympodially, infrequently circinate; sporangia faintly yellowish, later brownish, 26 to 88 by 29 to $82 \mu \mathrm{m}$; columellae globose to subglobose, 15 to 50 by 15 to $42 \mu \mathrm{m}$; sporangiospores variable in size and shape, ellipsoidal, infrequently large and bizarre, 4.3 to 8.6 by 2.7 to $6.4 \mu \mathrm{m}$. These morphological characteristics were in agreement with the descriptions of M. circinelloides f. lusitanicus (Schipper 1976).
Isolate X1899, identified as $M$. circinelloides $\mathrm{f}$. circinelloides based on ITS sequence, had a colony up to $5 \mathrm{~mm}$ in height, white to grayish; sporangiophores branched sympodially with long and short branches, the latter circinate; sporangia pale brown to pale gray, ranging from 31 to 87 by 30 to $87 \mu \mathrm{m}$; columellae obovoid to ellipsoidal in the larger sporangia, globose in the smaller sporangia, 17 to 47 by 17 to $48 \mu \mathrm{m}$; sporangiospores ellipsoidal to subglobose, 4.2 to 10.4 by 2.7 to $5.6 \mu \mathrm{m}$, clamydospores few in number. These morphological characteristics were in agreement with the descriptions of M. circinelloides f. circinelloides (Schipper 1976).

Isolates X1946 and X2121, identified as M. hiemalis based on ITS sequences, had a colony up to $15 \mathrm{~mm}$ in height, buff yellow; sporangiophores branched sympodially; sporangia yellowish to pale brown, 44 to 79 by 43 to $94 \mu \mathrm{m}$; columellae subglobose to ellipsoidal with truncate base, 22 to 50 by 22 to $45 \mu \mathrm{m}$; sporangiospores subglobose to ellipsoidal, sometimes flattened at one side, containing scattered granules, 4.7 to 9.4 by 2.5 to $6.6 \mu \mathrm{m}$. These morphological characteristics were in agreement with the descriptions of $M$. hiemalis (Schipper 1973).

Isolate X2142, identified as M. mucedo based on ITS sequence, had a colony up to $20 \mathrm{~mm}$ in height, white grayish; sporangiophores usually unbranched; sporangia whitish to yellowish at first, light brownish to gray at maturity, 51 to 153 by 55 to $138 \mu \mathrm{m}$; columellae obovoid to ellipsoidal, 48 to 136 by 33 to $85 \mu \mathrm{m}$; sporangiospores broadly ellipsoidal, frequently containing "cloudy" granules, 9.0 to 16.0 by 5.2 to $10.2 \mu \mathrm{m}$. These morphological characteristics were in agreement with the descriptions of M. mucedo (Schipper 1975).

Mycelial growth on different media. The five Mucor spp. were able to grow on the four media at $20^{\circ} \mathrm{C}$ with varying mycelial growth rates (Table 3; Fig. 3). Media significantly affected mycelial growth of Mucor spp. Regardless of media, M. piriformis (X1816) grew significantly faster than the other four species, and $M$. circinelloides f. lusitanicus (X1785) grew faster than M. racemosus f. racemosus, M. hiemalis, M. mucedo, and M. circinelloides f. circinelloides (X1899) (Table 3). SMA was the best for mycelial growth of M. piriformis and M. circinelloides f. circinelloides (X1899), while OJA was the best for mycelial growth of $M$. racemosus f. racemosus, M. hiemalis, and M. circinelloides f. lusitanicus (X1785). BWA
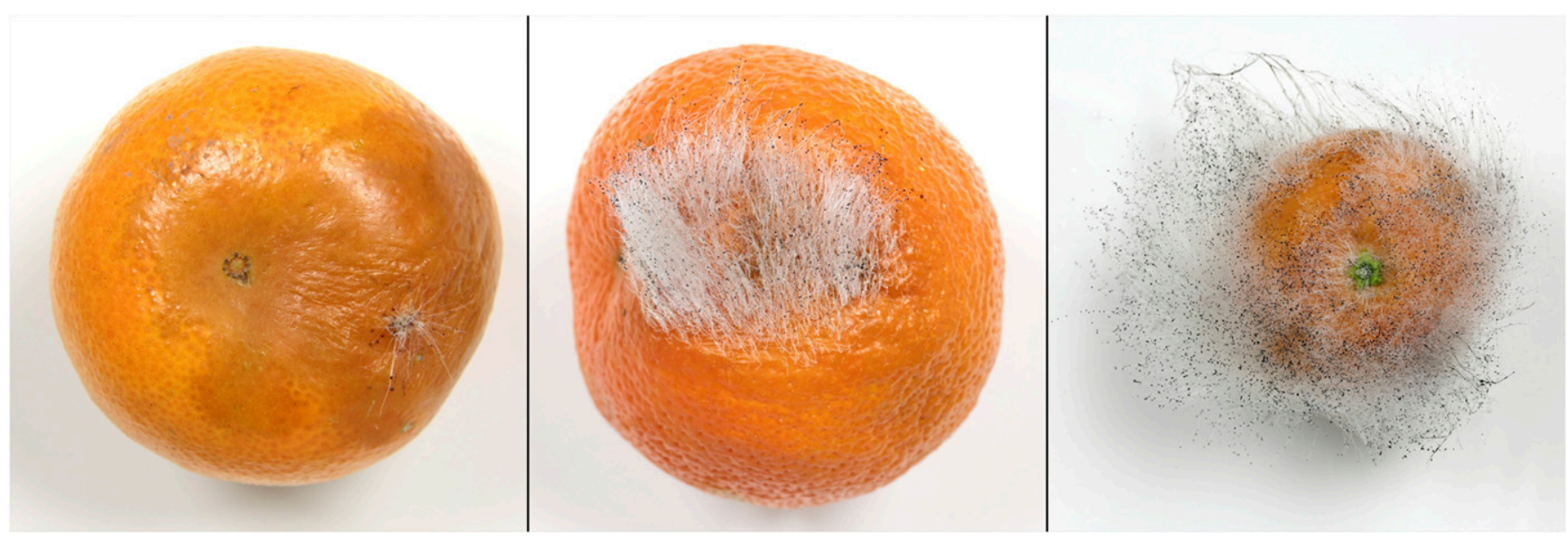

Fig. 1. Symptoms of Mucor rot caused by Mucor piriformis on mandarin fruit collected from citrus packinghouses.

Table 1. Percentages of Mucor rot in decayed mandarin fruit sampled from 15 grower lots in three packing houses in 2015

\begin{tabular}{|c|c|c|c|c|c|c|c|c|c|c|c|c|c|c|c|}
\hline \multirow[b]{4}{*}{ Fruit and rot } & \multicolumn{15}{|c|}{ Date, packinghouse (I to III), grower lots (A to O) } \\
\hline & \multirow{2}{*}{\multicolumn{2}{|c|}{$\frac{17 \text { March }}{\text { I }}$}} & \multirow{2}{*}{\multicolumn{3}{|c|}{$\frac{24 \text { March }}{\text { II }}$}} & \multirow{2}{*}{\multicolumn{3}{|c|}{$\frac{27 \text { March }}{\text { III }}$}} & \multirow{2}{*}{\multicolumn{2}{|c|}{$\frac{8 \text { April }}{\text { III }}$}} & \multirow{2}{*}{\multicolumn{2}{|c|}{$\frac{14 \text { April }}{\text { II }}$}} & \multirow{2}{*}{\multicolumn{3}{|c|}{$\frac{21 \text { April }}{\text { I }}$}} \\
\hline & & & & & & & & & & & & & & & \\
\hline & $\mathbf{A}$ & B & $\mathbf{C}$ & D & $\mathbf{E}$ & $\mathbf{F}$ & $\mathbf{G}$ & $\mathbf{H}$ & $\mathbf{I}$ & $\mathbf{J}$ & $\mathbf{K}$ & $\mathbf{L}$ & M & $\mathbf{N}$ & $\mathbf{O}$ \\
\hline Number of fruit & 60 & 30 & 59 & 30 & 30 & 30 & 45 & 30 & 30 & 29 & 60 & 30 & 30 & 30 & 30 \\
\hline Mucor rot $(\%)$ & 5.0 & 0 & 78.0 & 50.0 & 63.3 & 0 & 26.7 & 73.3 & 80.0 & 93.1 & 38.3 & 30.0 & 0 & 0 & 3.3 \\
\hline
\end{tabular}


was the best for mycelial growth of $M$. mucedo (Table 3). In general, for all isolates tested, mycelial growth on PDA was relatively poor while that on OJA was relatively good (Table 3; Fig. 3). Colony color of isolates X1650 (M. racemosus f. racemosus), X1899 (M. circinelloides f. circinelloides), and X2142 (M. mucedo) was media dependent (Fig. 3). For isolate X1650 (M. racemosus f. racemosus), the colony appeared slightly brown on PDA, white on SMA, and white-olive green on BWA (Fig. 3). For isolate X1899 (M. circinelloides $\mathrm{f}$. circinelloides), the colony appeared dense on PDA and light gray in the center on BWA (Fig. 3). For isolate X2142 (M. mucedo), the colony appeared light brown on PDA and light gray in the center on BWA (Fig. 3).

Mycelial growth at different temperatures. Radial mycelial growth rates in response to different temperatures varied among the five Mucor spp. (Fig. 4). Except for the seven isolates of M. circinelloides, all isolates grew at $0^{\circ} \mathrm{C}$ (Fig. 4). Except for the two isolates of M. piriformis, all isolates grew at $30^{\circ} \mathrm{C}$. Isolate $\mathrm{X} 1899$ (M. circinelloides f. circinelloides) was the only one that was able to grow at $35^{\circ} \mathrm{C}$ (Fig. 4). Optimal temperature for mycelial growth was $20^{\circ} \mathrm{C}$ for $M$. piriformis and $M$. mucedo, $25^{\circ} \mathrm{C}$ for $M$. racemosus f. racemosus and $M$. hiemalis, $27^{\circ} \mathrm{C}$ for the six isolates of $\mathrm{M}$. circinelloides f. lusitanicus, and $30^{\circ} \mathrm{C}$ for isolate X1899 (M. circinelloides f. circinelloides) (Fig. 4). At $27^{\circ} \mathrm{C}$, the two isolates of $M$. piriformis grew in a yeast fashion but they stopped growing on the third day of experiment, and they did not resume mycelial growth when incubated at $20^{\circ} \mathrm{C}$ after removal from $27^{\circ} \mathrm{C}$. The six isolates of $M$. circinelloides $\mathrm{f}$. lusitanicus showed a similar growth curve at each temperature; thus, only the result of isolate X1785 was shown in Figure 4. M. racemosus f. racemosus, M. hiemalis, M. mucedo, and

Table 2. Dimension of sporangiospores, sporangiophores, and columellae of the five Mucor spp. on potato dextrose agar (PDA) and beerwort agar (BWA) incubated at $20^{\circ} \mathrm{C}$ in the dark for 1 week ${ }^{\mathrm{y}}$

\begin{tabular}{|c|c|c|c|c|c|c|c|c|}
\hline \multirow[b]{3}{*}{ Species, isolate ${ }^{\mathrm{z}}$} & \multicolumn{4}{|c|}{ Sporangiospores } & \multicolumn{2}{|c|}{ Sporangia } & \multicolumn{2}{|c|}{ Columellae } \\
\hline & \multicolumn{2}{|r|}{ PDA } & \multicolumn{2}{|r|}{ BWA } & \multirow{2}{*}{$\begin{array}{c}\text { PDA } \\
\text { Range }(\mu \mathrm{m})\end{array}$} & \multirow{2}{*}{$\frac{\text { BWA }}{\text { Range }(\mu \mathrm{m})}$} & \multirow{2}{*}{$\begin{array}{c}\text { PDA } \\
\text { Range }(\mu \mathrm{m})\end{array}$} & \multirow{2}{*}{$\begin{array}{c}\text { BWA } \\
\text { Range }(\mu \mathrm{m})\end{array}$} \\
\hline & $\operatorname{Avg}(\mu \mathrm{m})$ & Range $(\mu \mathbf{m})$ & $\operatorname{Avg}(\mu \mathrm{m})$ & Range $(\mu \mathrm{m})$ & & & & \\
\hline \multicolumn{9}{|l|}{ Mucor piriformis } \\
\hline $\mathrm{X} 1816$ & 8.1 by 5.5 & $5.0-12.5$ by $3.2-11.4$ & 8.1 by 5.9 & $4.9-10.9$ by $3.6-8.0$ & $73-241$ by $80-279$ & $78-276$ by $93-274$ & $59-203$ by $55-170$ & $75-207$ by $47-186$ \\
\hline X1944 & 8.8 by 6.2 & $5.4-12.9$ by $3.0-12.1$ & 7.3 by 5.3 & $4.7-10.7$ by $3.0-9.5$ & $80-249$ by $81-237$ & $113-279$ by $110-288$ & $57-207$ by $45-163$ & $79-203$ by $45-181$ \\
\hline \multicolumn{9}{|l|}{ M. racemosus } \\
\hline $\mathrm{X} 1650$ & 7.6 by 5.8 & $5.0-9.9$ by $3.9-8.1$ & 6.8 by 5.6 & $4.3-8.4$ by $3.5-7.1$ & $44-83$ by $38-82$ & $25-80$ by $25-72$ & $23-53$ by $14-38$ & $14-43$ by $14-30$ \\
\hline X2081 & 7.1 by 5.7 & $4.9-9.4$ by $3.8-7.4$ & 7.1 by 6.0 & $4.9-10.1$ by $3.8-7.9$ & $39-79$ by $39-78$ & $31-90$ by $32-89$ & $22-52$ by $18-38$ & $21-55$ by $18-43$ \\
\hline \multicolumn{9}{|l|}{ M. circinelloides } \\
\hline $\mathrm{X} 1785$ & 6.6 by 4.6 & $4.0-11.1$ by $2.9-9.0$ & 6.2 by 4.1 & $4.3-8.4$ by $2.7-6.4$ & $33-87$ by $32-79$ & $26-88$ by $29-82$ & $13-52$ by $12-43$ & $15-50$ by $15-39$ \\
\hline X1899 & 6.0 by 4.5 & $3.4-11.4$ by $3.4-8.8$ & 5.8 by 4.0 & $4.2-10.4$ by $2.7-5.6$ & $39-94$ by $41-92$ & $31-87$ by $30-87$ & $21-44$ by $20-43$ & $17-47$ by $17-48$ \\
\hline X1935 & 6.8 by 4.5 & $4.8-9.7$ by $3.0-7.2$ & 6.1 by 3.8 & $4.3-8.6$ by $3.0-5.9$ & $32-75$ by $30-76$ & $35-76$ by $34-80$ & $21-51$ by $18-48$ & $21-48$ by $18-42$ \\
\hline \multicolumn{9}{|l|}{ M. hiemalis } \\
\hline X1946 & 7.2 by 5.1 & $5.0-9.8$ by $3.2-7.5$ & 6.8 by 4.3 & $4.7-9.4$ by $2.5-6.6$ & $44-79$ by $47-85$ & $45-90$ by $48-90$ & $28-44$ by $26-39$ & $22-50$ by $23-45$ \\
\hline X2121 & 6.9 by 4.8 & 4.6. -9.3 by $3.2-7.4$ & 6.5 by 3.9 & $4.9-8.5$ by $3.0-5.3$ & $49-75$ by $49-79$ & $37-94$ by $43-94$ & $27-47$ by $27-41$ & $22-43$ by $22-40$ \\
\hline \multicolumn{9}{|l|}{ M. mucedo } \\
\hline X2142 & 14.5 by 7.9 & $6.7 .-18.3$ by $6.0-10.3$ & 12.6 by 7.5 & $9.0-16.0$ by $5.2-10.2$ & $65-170$ by $75-177$ & $51-153$ by $55-138$ & $65-175$ by $42-121$ & $48-136$ by $33-85$ \\
\hline
\end{tabular}

y Avg $=$ average and Range $=$ size range

${ }^{z}$ X1785 and X1935, M. circinelloides f. lusitanicus; X1899, M. circinelloides f. circinelloides

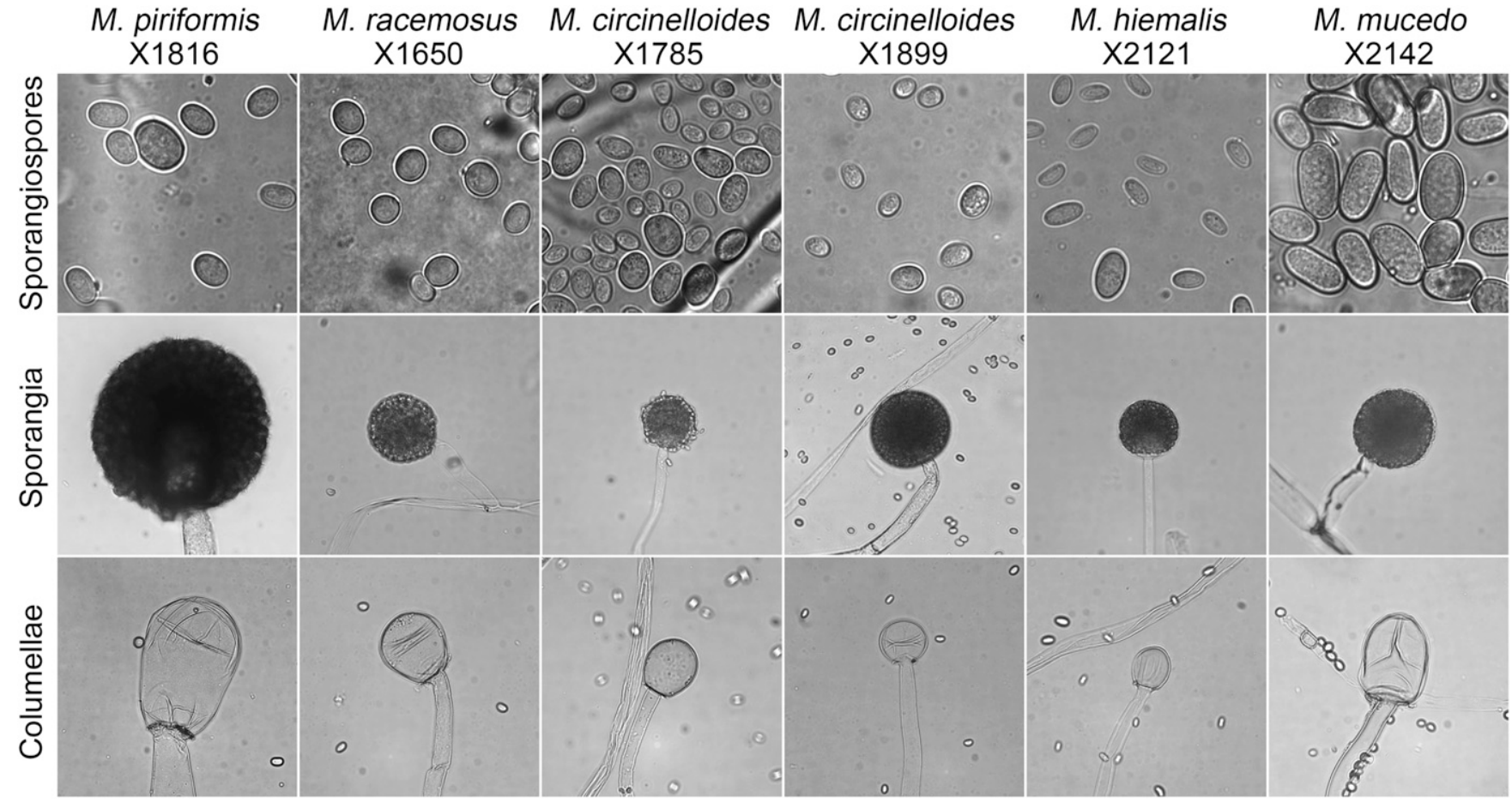

Fig. 2. Photomicrographs of representative sporangiospores, sporangia, and columellae of five Mucor spp. Microscopy was performed on cultures grown on beerwort agar. The height of each micrograph is scaled to $50 \mu \mathrm{m}$ for sporangiospores and $150 \mu \mathrm{m}$ for sporangia and columellae. X1650, Mucor racemosus f. racemosus; X1785, M. circinelloides f. lusitanicus; X1899, M. circinelloides f. circinelloides. 
the six isolates of $M$. circinelloides f. lusitanicus did not grow at $35^{\circ} \mathrm{C}$ (Fig. 4) but they resumed mycelial growth when incubated at $20^{\circ} \mathrm{C}$ after removal from $35^{\circ} \mathrm{C}$. Isolate X1899 (M. circinelloides f. circinelloides) did not grow at $40^{\circ} \mathrm{C}$ but resumed mycelial growth when incubated at $20^{\circ} \mathrm{C}$.

Radial mycelial growth rates at two temperatures were compared among the five Mucor spp. isolates (Table 4). These two temperatures $\left(5\right.$ and $\left.20^{\circ} \mathrm{C}\right)$ were chosen because they represent the temperatures used for storage of mandarin fruit in commercial packinghouses and that of retail stores, respectively. At these two temperatures, $M$. piriformis grew significantly faster than the other species, and $M$. mucedo was the most slow-growing one among the five species (Table 4).

Germination rate. Germination of sporangiospores was examined on SMA at two temperatures $\left(5\right.$ and $\left.20^{\circ} \mathrm{C}\right)$. Sporangiospores of $M$. piriformis, M. racemosus f. racemosus, and $M$. hiemalis germinated at both 5 and $20^{\circ} \mathrm{C}$ (Table 5). M. circinelloides germinated at $20^{\circ} \mathrm{C}$ but did not germinate at $5^{\circ} \mathrm{C}$ after incubation for $48 \mathrm{~h}$ (Table 5). When the incubation was extended to $96 \mathrm{~h}$ at $5^{\circ} \mathrm{C}$, germination rate was 4.9, 1.6, and 5.5\% for isolates X1785 (M. circinelloides $\mathrm{f}$. lusitanicus), X1899 (M. circinelloides f. circinelloides), and X1935 (M. circinelloides f. lusitanicus), respectively. M. mucedo (X2142) did not germinate on SMA at either 5 or $20^{\circ} \mathrm{C}$, and no germination was observed even after 72 and $24 \mathrm{~h}$ at 5 and $20^{\circ} \mathrm{C}$, respectively; however, the isolate germinated on OJA at both temperatures (Table 5). At $20^{\circ} \mathrm{C}$, germination rates of the two isolates of $M$. racemosus $\mathrm{f}$. racemosus were significantly higher than those of the others, while germination rates of the two isolates of $M$. piriformis were significantly higher than those of the others at $5^{\circ} \mathrm{C}$ (Table 5).

Pathogenicity. On the wound-inoculated mandarin fruit, all five Mucor spp. were able to cause decay (Fig. 5), and all inoculated fruit $(100 \%)$ developed Mucor rot symptoms at both 5 and $20^{\circ} \mathrm{C}$,

Table 3. Mycelial growth of the five Mucor spp. on four different media at $20^{\circ} \mathrm{C}$ for $48 \mathrm{~h}$ in the dark

\begin{tabular}{|c|c|c|c|c|c|c|}
\hline \multirow[b]{3}{*}{ Media $^{z}$} & \multicolumn{6}{|c|}{ Colony diameter $(\mathbf{m m})^{x}$} \\
\hline & \multirow{2}{*}{$\frac{\text { Mucor piriformis }}{\mathrm{X} 1816}$} & \multirow{2}{*}{$\frac{\text { M. racemosus }}{\mathrm{X} 1650}$} & \multicolumn{2}{|c|}{ M. circinelloides $^{\mathrm{y}}$} & \multirow{2}{*}{$\frac{\text { M. hiemalis }}{\mathrm{X} 2121}$} & \multirow{2}{*}{$\frac{\text { M. mucedo }}{\mathrm{X} 2142}$} \\
\hline & & & $\mathbf{X 1 7 8 5}$ & $\mathbf{X 1 8 9 9}$ & & \\
\hline PDA & $65.4 \mathrm{Ac}$ & $33.3 \mathrm{E} \mathrm{d}$ & $42.2 \mathrm{~B} \mathrm{c}$ & $36.3 \mathrm{D} \mathrm{c}$ & $38.1 \mathrm{C} \mathrm{d}$ & $37.7 \mathrm{C} \mathrm{c}$ \\
\hline SMA & $78.5 \mathrm{~A} \mathrm{a}$ & $41.1 \mathrm{E} \mathrm{c}$ & $50.2 \mathrm{~B} \mathrm{~b}$ & $47.4 \mathrm{C} \mathrm{a}$ & $42.2 \mathrm{D} \mathrm{c}$ & $33.6 \mathrm{~F} \mathrm{~d}$ \\
\hline BWA & $71.2 \mathrm{~A} \mathrm{~b}$ & $45.5 \mathrm{CD} \mathrm{b}$ & $49.6 \mathrm{~B} \mathrm{~b}$ & $34.8 \mathrm{E} \mathrm{d}$ & $45.1 \mathrm{D} \mathrm{b}$ & $46.2 \mathrm{C} \mathrm{a}$ \\
\hline OJA & $66.4 \mathrm{~A} \mathrm{c}$ & $52.1 \mathrm{C} \mathrm{a}$ & $56.1 \mathrm{~B} \mathrm{a}$ & $43.2 \mathrm{D} \mathrm{b}$ & $51.9 \mathrm{C} \mathrm{a}$ & $42.8 \mathrm{D} \mathrm{b}$ \\
\hline
\end{tabular}

${ }^{x}$ Values followed by the same uppercase letter within the same row or the same lowercase letter within the same column are not significantly different $(P=0.05)$ according to Tukey's honestly significant difference tests.

y X1785, M. circinelloides f. lusitanicus and X1899, M. circinelloides f. circinelloides.

z $\mathrm{PDA}=$ potato dextrose agar, SMA = synthetic Mucor agar, BWA = beer wort agar, and OJA = orange juice agar.

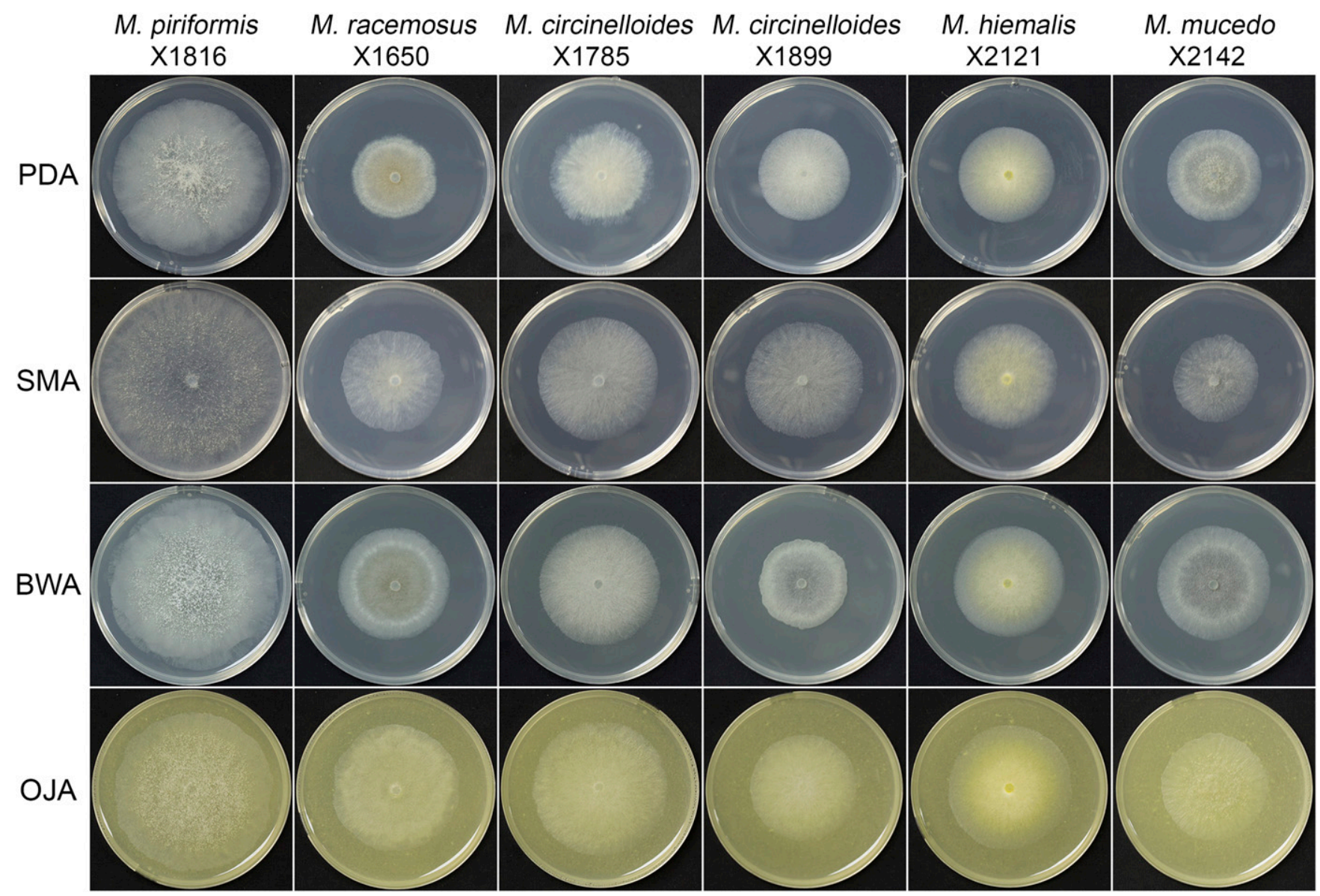

Fig. 3. Colony morphology of the five Mucor spp. on four different media incubated in the dark at $20^{\circ} \mathrm{C}$ for $48 \mathrm{~h}$. PDA $=$ potato dextrose agar, SMA $=$ synthetic Mucor agar, $B W A=$ beer wort agar, and OJA = orange juice agar. X1650, Mucor racemosus f. racemosus; X1785, M. circinelloides f. lusitanicus; X1899, M. circinelloides f. circinelloides. 
regardless of the species. No decay symptoms were observed on noninoculated control fruit.

The following descriptions of the disease symptoms were made on mandarin fruit that were wounded, inoculated with Mucor spp., and incubated at $5^{\circ} \mathrm{C}$.

Symptoms on the fruit inoculated with $M$. piriformis started to appear about 1 week after inoculation. Infected tissues of the rind became soft and light to dark brown. As infections advanced, the lesions around the wound formed a quasicircular or irregular shape, slightly shrunk inwardly, forming wrinkles on the surface, and sporangiophores protruded through the wound. When the decayed fruit was cut, the fruit flesh appeared to be completely rotten, light to dark brown, very soft or watery, and separated easily from the healthy tissue, and sporangiophores often were present in the empty space inside the fruit (Fig. 5A and G).

Symptoms on the fruit inoculated with $M$. racemosus f. racemosus appeared 2 weeks after inoculation. Only a small lesion (less than $10 \mathrm{~mm}$ in diameter) developed around the wound and became soft and dark brown. White sporangiophores protruded through the

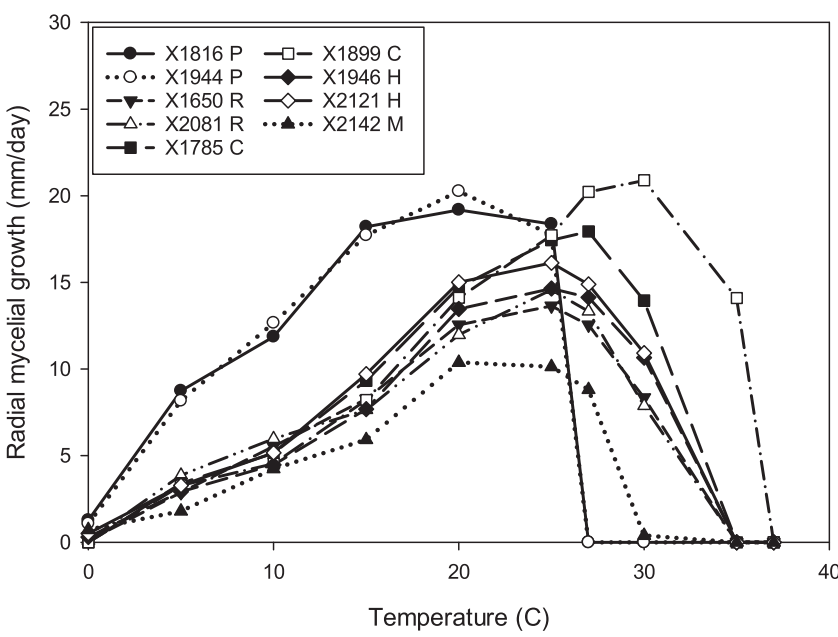

Fig. 4. Radial mycelial growth of the Mucor spp. on synthetic Mucor agar at various temperatures. Isolate names are followed by the initial letters of the species: $\mathrm{P}=$ Mucor piriformis, $\mathrm{R}=M$. racemosus $\mathrm{f}$. racemosus, $\mathrm{C}=\mathrm{M}$. circinelloides $(\mathrm{X} 1785=$ $M$. circinelloides f. lusitanicus and $\mathrm{X} 1899=M$. circinelloides $f$. circinelloides), $\mathrm{H}=\mathrm{M}$. hiemalis, and $\mathrm{M}=\mathrm{M}$. mucedo. wound, forming a small mass around the wound. When the fruit was cut, infected flesh appeared to be rotten, very soft or watery, and separated easily from the healthy tissue (Fig. 5B and $\mathrm{H}$ ).

Symptoms on the fruit inoculated with $M$. circinelloides f. lusitanicus (X1785) appeared 2 weeks after the inoculation. Only a very small lesion was evident around the wound (about 5 to $7 \mathrm{~mm}$ in diameter) and became light or dark brown. Infrequently, very fine and white sporangiophores protruded through the wound, forming a flat thin layer over the wound. Often, no sporangiophores were observed around the wound. Decayed flesh inside the fruit became light yellowish, or no color change, and the decayed tissue became very soft and watery, and separated easily from the healthy tissue (Fig. $5 \mathrm{C}$ and I).

On the fruit inoculated with $M$. circinelloides f. circinelloides (X1899), no external symptoms were evident on the rind of the fruit during the course of experiments at both 5 and $20^{\circ} \mathrm{C}$. No color change and no sporangiophores around the wound were observed. However, when the fruit was cut, the flesh under the wound became decayed and was light brown and very soft and watery, and separated easily from the healthy tissue (Fig. 5D and J).

Symptoms on the fruit inoculated with M. hiemalis (X2121) appeared 2 weeks after the inoculation. Only a small lesion (5 to $10 \mathrm{~mm}$ ) developed around the wound, and the color of the lesion turned light or dark brown. Frequently, few and extremely thin sporangiophores protruded through the wound. Decayed flesh became light or dark brown and was very soft or watery, and separated easily from the healthy tissue (Fig. 5E and K).

Symptoms on the fruit inoculated with M. mucedo (X2142) were similar to those caused by $M$. hiemalis, but gray to dark masses of sporangiophores were often seen in the affected fruit flesh (Fig. 5F and $\mathrm{L}$ ).

For all Mucor spp. tested at $20^{\circ} \mathrm{C}$, the disease symptoms were similar to those observed at $5^{\circ} \mathrm{C}$, except that the symptoms progressed faster. The five Mucor spp. were reisolated from decayed fruit that were inoculated with respective species.

On the cut fruit inoculated with the fungi, all Mucor spp. isolates tested were able to cause decay on mandarin fruit at both 5 and $20^{\circ} \mathrm{C}$. No decay symptoms were observed on noninoculated control fruit. At $5^{\circ} \mathrm{C}$, the two isolates of M. piriformis, X1816 and X1944, appeared to be the most virulent because the lesion sizes on the fruit inoculated with $M$. piriformis were the largest, followed by M. mucedo (X2142), M. racemosus f. racemosus (X1650), M. hiemalis (X2121), and M. circinelloides f. lusitanicus (X1785) (Table 6; Fig. 5). M. circinelloides f. circinelloides (X1899) resulted in no or very small

Table 4. Radial mycelial growth of the five Mucor spp. on synthetic Mucor agar at 5 and $20^{\circ} \mathrm{C}$ in the dark

\begin{tabular}{|c|c|c|c|c|c|c|c|c|c|}
\hline \multirow[b]{3}{*}{ Temperature } & \multicolumn{9}{|c|}{ Mycelial growth (mm/day)y } \\
\hline & \multicolumn{2}{|c|}{ Mucor piriformis } & \multicolumn{2}{|c|}{ M. racemosus } & \multicolumn{2}{|c|}{ M. circinelloides $^{\mathbf{Z}}$} & \multicolumn{2}{|c|}{ M. hiemalis } & \multirow{2}{*}{$\frac{\text { M. mucedo }}{\mathrm{X} 2142}$} \\
\hline & X1816 & X1944 & X1650 & X2081 & X1785 & X1899 & X1946 & $\mathbf{X 2 1 2 1}$ & \\
\hline $5^{\circ} \mathrm{C}$ & $8.7 \mathrm{a}$ & $8.2 \mathrm{a}$ & $2.8 \mathrm{bc}$ & $3.9 \mathrm{~b}$ & $3.4 \mathrm{~b}$ & $3.3 \mathrm{~b}$ & $2.9 \mathrm{~b}$ & $3.3 \mathrm{~b}$ & $1.8 \mathrm{c}$ \\
\hline $20^{\circ} \mathrm{C}$ & $19.2 \mathrm{~b}$ & $20.3 \mathrm{a}$ & $12.5 \mathrm{f}$ & $12.0 \mathrm{f}$ & $14.7 \mathrm{~cd}$ & $14.1 \mathrm{de}$ & $13.5 \mathrm{e}$ & $15.0 \mathrm{c}$ & $10.4 \mathrm{~g}$ \\
\hline
\end{tabular}

y Values followed by the same letter within the same row are not significantly different $(P=0.05)$ according to Tukey's honestly significant difference tests.

${ }^{z}$ X1785, M. circinelloides $\mathrm{f}$. lusitanicus and X1899, M. circinelloides $\mathrm{f}$. circinelloides.

Table 5. Germination rate of sporangiospores of the five Mucor spp. on synthetic Mucor agar

\begin{tabular}{|c|c|c|c|c|c|c|c|c|c|c|}
\hline \multirow[b]{3}{*}{ Temperature $^{\mathrm{z}}$} & \multicolumn{10}{|c|}{ Germination rate $(\%)^{\mathrm{w}}$} \\
\hline & \multicolumn{2}{|c|}{ Mucor piriformis } & \multicolumn{2}{|c|}{ M. racemosus } & \multicolumn{3}{|c|}{ M. circinelloides $^{\mathrm{x}}$} & \multicolumn{2}{|c|}{ M. hiemalis } & \multirow{2}{*}{$\frac{\text { M. mucedo }}{\mathrm{X} 2142}$} \\
\hline & X1816 & X1944 & X1650 & X2081 & X1785 & X1899 & X1935 & X1946 & $\mathrm{X} 2121$ & \\
\hline $5^{\circ} \mathrm{C}$ & $88.0 \mathrm{a}$ & $83.2 \mathrm{a}$ & $20.6 \mathrm{c}$ & $18.7 \mathrm{c}$ & $0 \mathrm{e}$ & $0 \mathrm{e}$ & $0 \mathrm{e}$ & $7.1 \mathrm{~d}$ & $44.3 \mathrm{~b}$ & 0 e (19.2) \\
\hline $20^{\circ} \mathrm{C}$ & $76.2 \mathrm{de}$ & $82.1 \mathrm{dc}$ & $96.1 \mathrm{a}$ & $94.2 \mathrm{ab}$ & $68.0 \mathrm{e}$ & $44.9 \mathrm{f}$ & $66.3 \mathrm{e}$ & $72.3 \mathrm{de}$ & $89.1 \mathrm{bc}$ & $0 \mathrm{~g}(44.8)$ \\
\hline
\end{tabular}

${ }^{\text {w }}$ Values followed by the same letter within the same row are not significantly different $(P=0.05)$ according to Tukey's honestly significant difference tests.

${ }^{x}$ X1785 and X1935, M. circinelloides $\mathrm{f}$. lusitanicus and X1899, M. circinelloides f. circinelloides.

${ }^{y}$ M. mucedo (X2142) did not germinate on synthetic Mucor agar at these two temperatures but germinated on orange juice agar, and the numbers in parenthesis are the germination rates on orange juice agar.

$\mathrm{z}$ Incubated in the dark at $5^{\circ} \mathrm{C}$ for $48 \mathrm{~h}$ or $20^{\circ} \mathrm{C}$ for $14 \mathrm{~h}$. 
lesions 9 days after incubation at $5^{\circ} \mathrm{C}$ but was able to develop symptoms on the inoculated fruit after an additional 10-day incubation at $5^{\circ} \mathrm{C}$. At $20^{\circ} \mathrm{C}, M$. piriformis also appeared to be the most virulent species in comparison with the other species and $M$. hiemalis was least virulent, while $M$. racemosus f. racemosus, $M$. circinelloides, and $M$. mucedo did not differ significantly in lesion size (Table 6).

\section{Discussion}

This is the first report of Mucor rot in stored mandarin fruit in California. We documented that Mucor rot in mandarin in California was caused by five Mucor spp., consisting of $M$. piriformis, M. circinelloides, $M$. racemosus, $M$. hiemalis, and $M$. mucedo, and that $M$. piriformis was the dominant species, accounting for over $92 \%$ of the Mucor rot-decayed mandarin fruit sampled from three commercial citrus packinghouses, though the other four Mucor spp. were also pathogenic to mandarin fruit.

Previously, two Mucor spp., M. racemosus and M. paronychius (originally M. paronychia), were reported as citrus pathogens (Farr and Rossman 2015; Timmer and Menge 2000). M. paronychius was reported as a new Mucor sp. causing fingernail infection among workers who squeezed cull orange fruit with bare hands (Sutherland-Campbell and Plunkett 1934). However, the establishment of M. paronychius as a species is considered questionable and this species was not studied by other authors (Farr et al. 1989; Walther et al. 2013). M. paronychius was neither included in the morphological studies on all accepted Mucor spp. by Schipper $(1973,1975,1976,1978)$ nor present in the phylogenetic analyses based on ITS or LSU D1/D2 region of the large ribosomal subunit sequencing in the order Mucorales by Walther et al. (2013). A large number of Mucor spp. names have been synonymized but we could not find such information about $M$. paronychius. Although Mucor rot in citrus has never been included in major widely used references for citrus diseases such as "Compendium of Citrus Diseases" (Timmer et al. 2000) or "A Color Atlas of Post-harvest Disease and Disorders of Fruits and Vegetables" (Snowdon 1990), association of Mucor spp. with decayed citrus fruit has recently been reported elsewhere. Bukar et al. (2009) conducted a pathogen survey in sweet orange (Citrus sinensis) in Nigeria and found that $25 \%$ of decayed fruit were associated with Mucor spp. Similarly, Akhtar et al. (2013) reported that $1.65 \%$ of decayed citrus collected from

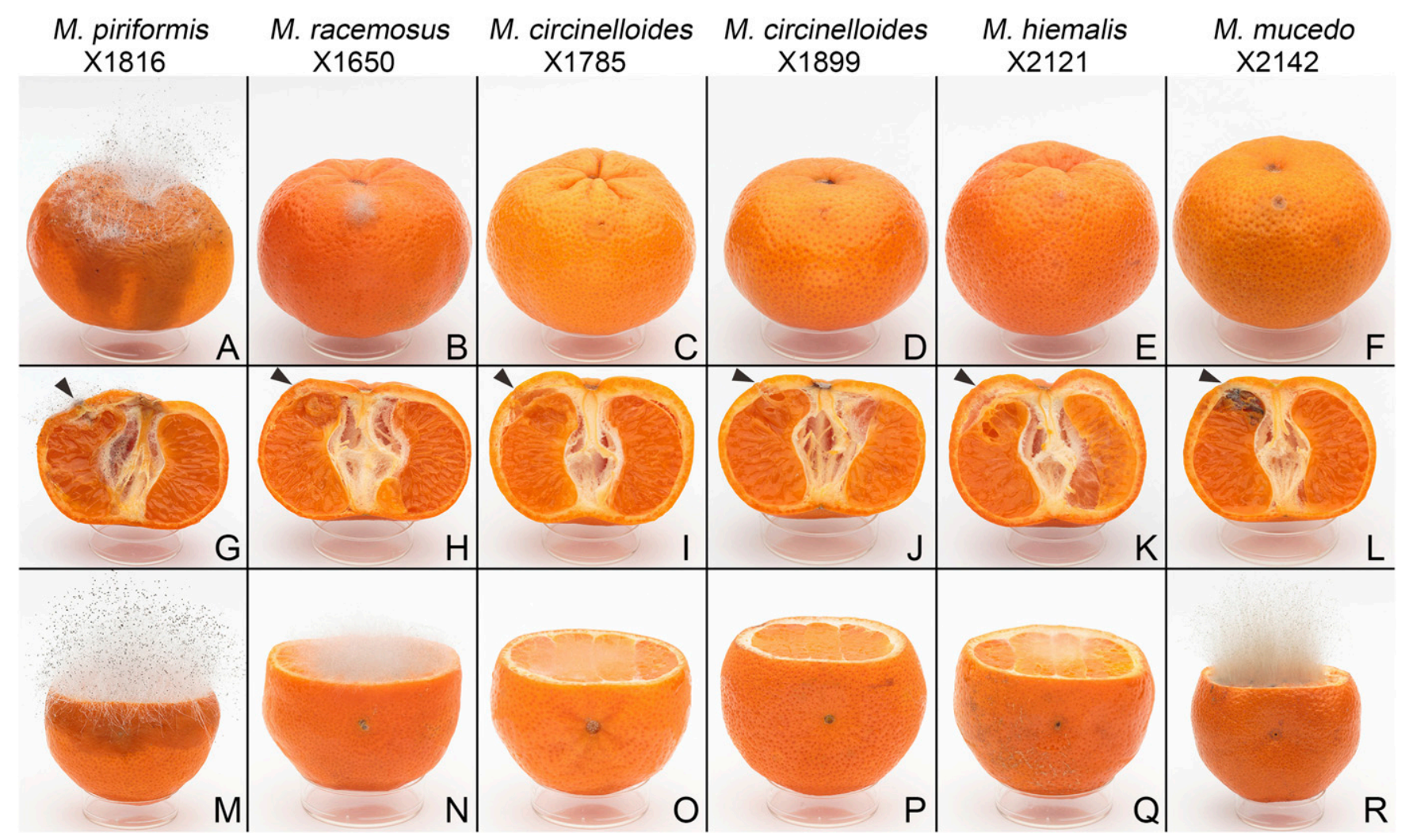

Fig. 5. Symptoms of Mucor rot on mandarin fruit inoculated with representative isolates of the five Mucor spp. A, G, and $\mathbf{M}, \mathbf{M u c o r}$ piriformis; $\mathbf{B}$, H, and N, M. racemosus f. racemosus; C, I, and O, X1785, M. circinelloides f. lusitanicus; D, J, and P, X1899, M. circinelloides f. circinelloides; E, K, and Q, M. hiemalis; and F, L, and R, M. mucedo. A to F, Fruit that were wounded, inoculated, and incubated at $5^{\circ} \mathrm{C}$ for 16 days in the dark; $\mathbf{G}$ to $\mathbf{L}$, internal symptoms of the wound-inoculated fruit; and $\mathbf{M}$ to $\mathbf{R}$, symptoms on the sliced fruit that were inoculated with the pathogen and incubated at $5^{\circ} \mathrm{C}$ for 15 days in the dark. Arrows indicate wound and inoculation sites.

Table 6. Lesion size (diameter in $\mathrm{mm}$ ) on cut mandarin fruit inoculated with Mucor spp.

\begin{tabular}{|c|c|c|c|c|c|c|c|}
\hline \multirow[b]{3}{*}{ Temperature ${ }^{y}$} & \multicolumn{7}{|c|}{ Lesion diameter $(\mathbf{m m})^{\mathbf{w}}$} \\
\hline & \multicolumn{2}{|c|}{ Mucor piriformis } & \multirow{2}{*}{$\frac{\text { M. racemosus }}{\mathrm{X} 1650}$} & \multicolumn{2}{|c|}{ M. circinelloides ${ }^{\mathrm{x}}$} & \multirow{2}{*}{$\frac{\text { M. hiemalis }}{\mathrm{X} 2121}$} & \multirow{2}{*}{$\frac{\text { M. mucedo }}{\mathrm{X} 2142}$} \\
\hline & X1816 & X1944 & & X1785 & X1899 & & \\
\hline $5^{\circ} \mathrm{C}$ & $34.7 \mathrm{a}$ & $33.1 \mathrm{a}$ & $20.3 \mathrm{c}$ & $11.5 \mathrm{~d}$ & $17.0^{\mathrm{z}}$ & $14.4 \mathrm{~d}$ & $28.8 \mathrm{~b}$ \\
\hline $20^{\circ} \mathrm{C}$ & $30.6 \mathrm{a}$ & $29.7 \mathrm{a}$ & $24.4 \mathrm{bc}$ & $22.1 \mathrm{c}$ & $20.6 \mathrm{c}$ & $16.7 \mathrm{~d}$ & $20.6 \mathrm{c}$ \\
\hline
\end{tabular}


cold-storage facilities in Pakistan were associated with Mucor spp. However, in both studies, Mucor spp. were not identified and no detailed descriptions of the disease symptoms were provided (Akhtar et al. 2013; Bukar et al. 2009). To the best of our knowledge, our study is the first report of Mucor rot in citrus fruit caused by M. piriformis, M. circinelloides, $M$. hiemalis, and $M$. mucedo.

Identification of Mucor spp. has traditionally been based on morphological characteristics and mating experiments, mainly studied by Schipper (1973, 1975, 1976, 1978). Recently, DNA barcoding markers have been successfully used for identification of species in the order Mucorales (Meyer and Gams 2003; Vitale et al. 2012; Walther et al. 2013). Walther et al. (2013) sequenced ITS regions of 178 species of the 227 currently accepted species in the order Mucorales and found that ITS sequencing proved to be a reliable tool to identify species in the order Mucorales because of its discriminative power. In the present study, all Mucor isolates were identified to the species level based on ITS sequencing, following the approach of Walther et al. (2013). In the present study, the identification based on the ITS sequencing was further confirmed by the morphological characteristics of the five Mucor spp. that were examined under the same culture growth conditions as those described by Schipper $(1973,1975,1976,1978)$ and compared with the descriptions of Schipper. We found that the descriptions by Schipper (1973, 1975, 1976, 1978) were accurate for the five Mucor spp. examined in this study, and suggest that such descriptions should continue to be used to aid speciation of Mucor. DNA sequencing provides a fast approach for identification of fungi. However, because the ITS region is variable between members in the order Mucorales, ITS sequences of some species may differ to such an extent that they could not be aligned confidently with their putative sibling species (Walther et al. 2013). Thus, in addition to ITS sequencing, examination of morphological characteristics is still necessary for accurate identification of Mucor spp.

We found that $M$. piriformis was the primary species responsible for Mucor rot in mandarin fruit. This finding is similar to Mucor rot in pome and stone fruit in California and the U.S. Pacific Northwest (Michailides and Spotts 1990b). In apple and pear, M. piriformis is the primary cause of Mucor rot, though M. mucedo, M. racemosus, and $M$. strictus have also been reported to cause decay (Spotts 2014). In stone fruit in California, Mucor spp. causing Mucor rot were recovered from orchard soils and identified as M. piriformis, M. racemosus, M. circinelloides, M. hiemalis, M. plumbeus, and M. genevensis (Michailides 1991). M. piriformis and other Mucor spp. are soilborne pathogens. They live as saprophytes in the soil. In the Central Valley of California, stone fruit and, to a lesser extent, apple are also grown. Citrus fields may be surrounded by stone or pome fruit orchards. Citrus trees may also be planted to fields previously planted with stone or pome fruit. The similarity in Mucor spp. compositions between citrus and stone fruit in California suggests that these Mucor spp. may be commonly present in orchard soils of these fruit crops in the region and that potential spread of inoculum of these fungi among orchards of different fruit crops could contribute to the build up of pathogen populations in the field because spores of $M$. piriformis on decayed fruit on the orchard floor can be spread by rodents, birds, and insects such as nitidulid beetles and vinegar flies (Michailides and Spotts 1986, 1990a; Spotts 2014).

Populations of sporangiospores of $M$. piriformis in pome fruit orchard soils fluctuate annually in response to soil moisture, temperature, and nutrient availability (Dobson et al. 1989; Guo et al. 1999; Spotts and Cervantes 1986). M. piriformis survives most successfully in cool, dry soils (Spotts and Cervantes 1986). In apple orchards in the Central Valley of California, populations of M. piriformis were highest during winter, declined during summer and fall, and increased again in winter and early spring of the following year (Guo et al. 1999). In the same region, mandarin fruit are harvested from late fall through winter to early spring, depending on cultivars (Kahn and Vidalakis 2014). The harvest time of mandarin fruit coincides with the occurrence of the highest populations of $M$. piriformis in apple orchard soils in the same region. If similar population dynamics of M. piriformis also occur in mandarin orchard soils, more inoculum would be available during fruit harvest, leading to a high risk of Mucor rot infections. Research is needed to understand the survival and population dynamics of $M$. piriformis under the current cultural practices and environmental conditions in citrus orchards in California.

All five Mucor spp. tested in this study were able to actively grow at $5^{\circ} \mathrm{C}$. The ability of these Mucor spp. to grow at the temperature $\left(5^{\circ} \mathrm{C}\right)$ commonly used for storage of mandarin fruit supports the findings from pathogenicity tests that these fungi have the ability to cause decay on mandarin fruit in cold storage because the cold temperatures do not prevent the growth of these fungi. $M$. piriformis grew significantly faster at $5^{\circ} \mathrm{C}$ than the other four Mucor spp., supporting the results observed in the pathogenicity tests that $M$. piriformis is more virulent on mandarin fruit than the other Mucor spp. The high virulence of $M$. piriformis is also supported by its higher sporangiospore germination rates at $5^{\circ} \mathrm{C}$ than those of the other four Mucor spp. Similarly, studies to compare virulence of six Mucor spp. on stone fruit indicated that $M$. piriformis also is the most virulent species (Michailides 1991). Because M. piriformis is the most dominant and virulent Mucor spp. responsible for Mucor rot in mandarin fruit in California, control of Mucor rot in mandarin should target this species.

In pome fruit, Mucor rot-decayed fruit at the advanced stages release large quantities of juice containing sporangiospores of $M$. piriformis, which can spread from decayed fruit to healthy fruit, resulting in more infections during storage. Secondary spread of Mucor rot in cold storage is common in pear but not in apple (Spotts 2014). Secondary spread of Mucor rot from decayed fruit to sound fruit via ungerminated sporangiospores of $M$. piriformis also was observed on stone fruit (Michailides 1991). We did not determine whether and how Mucor rot could spread from infected fruit to sound fruit in cold storage; however, nesting of Mucor rot-decayed fruit has been observed in mandarin cold storage. Future research is needed to further understand infections of mandarin fruit by $M$. piriformis during cold storage. In addition, research also is needed to determine whether Mucor spp. affect other types of citrus fruit in California.

In this study, decayed fruit were collected from grower lots that were presorted and had been stored at 4.4 to $7.2^{\circ} \mathrm{C}$ for a period of time. Citrus postharvest fungicides were commonly applied at presorting operations to control decays caused by $P$. digitatum, $P$. italicum, and G. citri-aurantii (McKay et al. 2012; Smilanick and Mansour 2007; Smilanick et al. 2006, 2008). It is likely that the current decay-control programs may not be effective against $M$. piriformis because some existing citrus postharvest fungicides such as thiabendazole, pyrimethanil, and fludioxonil are known to be ineffective in controlling $M$. piriformis as observed on pome fruit (Spotts 2014). Nonetheless, research is needed to evaluate the effectiveness of sanitizers and fungicides that are commonly used at citrus presorting and packing operations in controlling spores of Mucor spp. and Mucor rot.

\section{Acknowledgments}

This research was supported, in part, by the Citrus Research Board. We thank T. Ruiz, who first recognized the importance of this pathogen to the citrus industry, for his valuable contributions and continued cooperation; J. L. Smilanick, D. A. Margosan, and K. Fjeld for technical assistance; and the personnel of the three citrus packinghouses for assistance in sample collection.

\section{Literature Cited}

Akhtar, N., Anjum, T., and Jabeen, R. 2013. Isolation and identification of storage fungi from citrus sampled from major growing areas of Punjab, Pakistan. Int. J. Agric. Biol. 15:1283-1288.

Arpaia, M. L., Adaskaveg, J. E., Smilanick, J., and Elliot, R. 2014. Postharvest handling. Pages 369-382 in: Citrus Production Manual. L. Ferguson and E. E. Grafton-Cardwell, eds. University of California Agriculture and Natural Resources Publication 3539, Oakland.

Bhattarai, R. R., Rijal, R. K., and Mishra, P. 2013. Post-harvest losses in mandarin orange: A case study of Dhankuta district. Nepal. Afr. J. Agric. Res. 8:763-767.

Bukar, A., Mukhatar, M. D., and Adamu, S. 2009. Isolation and identification of postharvest spoilage fungi associated with sweet oranges traded in Kano metropolis. Bayero J. Pure Appl. Sci. 2:122-124.

CDFA-CASS. 2014. California citrus acreage report. Online publication. California Department of Food and Agriculture, California Agricultural 
Statistics Service, cooperating with United States Department of Agriculture National Agricultural Statistics Service. http://www.nass.usda.gov/Statistics by_State/California/Publications/Fruits_and_Nuts/201408citac.pdf

Dobson, R. L., Michailides, T. J., Cervantes, L. A., and Spotts, R. A. 1989. Population dynamics of Mucor piriformis in pear orchard soils as related to decaying pear fruit. Phytopathology 79:657-660.

Farr, D. F., Bills, G. F., Chamuris, G. P., and Rossman, A. Y. 1989. Fungi on Plants and Plant Products in the United States. American Phytopathological Society, St. Paul, MN.

Farr, D. F., and Rossman, A. Y. 2015. Fungal Databases, Systematic Mycology and Microbiology Laboratory, ARS, USDA. Online publication. http://nt.arsgrin.gov/fungaldatabases/

Guo, L. Y., Michailides, T. J., and Morgan, D. P. 1999. Survival of Mucor piriformis in soil of apple orchards in California. Plant Dis. 83:189-193.

Hall, T. A. 1999. BioEdit: A user-friendly biological sequence alignment editor and analysis program for Windows 95/98/NT. Nucleic Acids. Symp. Ser. 41: 95-98

Kahn, T., and Vidalakis, G. 2014. Scion Cultivars. Pages 63-93 in: Citrus Production Manual. L. Ferguson and E. E. Grafton-Cardwell, eds. University of California Agriculture and Natural Resources Publication 3539, Oakland.

Ladaniya, M. 2008. Citrus Fruit: Biology, Technology and Evaluation. Academic Press, San Diego, CA.

McKay, A. H., Förster, H., and Adaskaveg, J. E. 2012. Efficacy and application strategies for propiconazole as a new postharvest fungicide for managing sour rot and green mold of citrus fruit. Plant Dis. 96:235-242.

Michailides, T. J. 1991. Characterization and comparative studies of Mucor isolates from stone fruits from California and Chile. Plant Dis. 75:373-380.

Michailides, T. J., and Spotts, R. A. 1986. Factors affecting dispersal of Mucor piriformis in pear orchards and into the packinghouse. Plant Dis. 70: 1060-1063.

Michailides, T. J., and Spotts, R. A. 1990a. Transmission of Mucor piriformis to fruit of Prunus persica by Carpophilus spp. and Drosophila melanogaster. Plant Dis. 74:287-291.

Michailides, T. J., and Spotts, R. A. 1990b. Postharvest diseases of pome and stone fruits caused by Mucor piriformis in the Pacific Northwest and California. Plant Dis. 74:537-543.

Schipper, M. A. A. 1973. A study on variability in Mucor hiemalis and related species. Stud. Mycol. 4:1-40.

Schipper, M. A. A. 1975. On Mucor mucedo, Mucor flavus and related species. Stud. Mycol. 10:1-33.

Schipper, M. A. A. 1976. On Mucor circinelloides, Mucor racemosus and related species. Stud. Mycol. 12:1-40.

Schipper, M. A. A. 1978. On certain species of Mucor with a key to all accepted species. Stud. Mycol. 17:53-71.

Smilanick, J. L., and Mansour, M. F. 2007. Influence of temperature and humidity on survival of Penicillium digitatum and Geotrichum citri-aurantii. Plant Dis. 91:990-996.

Smilanick, J. L., Mansour, M. F., Gabler, F. M., and Soreson, D. 2008. Control of citrus postharvest green mold and sour rot by potassium sorbate combined with heat and fungicides. Postharvest Biol. Technol. 47:226-238.
Smilanick, J. L., Mansour, M. F., and Sorenson, D. 2006. Pre- and postharvest treatments to control green mold of citrus fruit during ethylene degreening. Plant Dis. 90:89-96.

Snowdon, A. L. 1990. Citrus fruits. Pages in 54-91: A Color Atlas of Post-Harvest Diseases and Disorders of Fruits and Vegetables, Vol. 1. CRC Press, Boca Raton, FL.

Spotts, R. A. 2014. Mucor Rot. Pages 80-81 in: Compendium of Apple and Pear Diseases and Pests, 2nd ed. T. B. Sutton, H. S. Aldwinckle, A. M. Agnello, and J. F. Walgenbach, eds. American Phytopathological Society, St. Paul, MN.

Spotts, R. A., and Cervantes, L. A. 1986. Populations, pathogenicity, and benomyl resistance of Botrytis spp., Penicillium spp., and Mucor piriformis in packinghouses. Plant Dis. 70:106-108.

Sutherland-Campbell, H., and Plunkett, O. A. 1934. Mucor paronychia. Arch Derm. Syphilol. 30:651-658.

Terol, J. C. A., Colmenero, J. M., Cercos, M., Tadeo, F., Agusti, J., Alos, E., Andres, F., Soler, G., Brumos, J., Iglesias, D. J., Gotz, S., Legaz, F., Argout, X., Courtois, B., Ollitrault, P., Dossat, C., Wincker, P., Morillon, R., and Talon, M. 2007. Analysis of 13000 unique Citrus clusters associated with fruit quality, production and salinity tolerance. BMC Genomics 8:31.

Timmer, L. W., Garnsey, S. M., and Graham, J. H. 2000. Compendium of Citrus Diseases, 2nd ed. American Phytopathological Society, St. Paul, MN.

Timmer, L. W., and Menge, J. A. 2000. Common Names of Plant Diseases. Diseases of Citrus. Online publication. http://www.apsnet.org/publications/ commonnames/Pages/Citrus.aspx

USDA-FAS. 2016. Citrus: World Markets and Trade. Online publication. United States Department of Agriculture Foreign Agricultural Service. http://apps.fas. usda.gov/psdonline/circulars/citrus.pdf

USDA-NASS. 2015. Citrus fruits, 2015 summary. Online publication. United States Department of Agriculture National Agricultural Statistics Service. http://usda.mannlib.cornell.edu/usda/current/CitrFrui/CitrFrui-09-17-2015. pdf

Vitale, R. G., de Hoog, G. S., Schwarz, P., Dannaoui, E., Deng, S., Machouart, M., Voigt, K., van de Sande, W. W. J., Dolatabadi, S., Meis, J. F., and Walther, G. 2012. Antifungal susceptibility and phylogeny of opportunistic members of the order Mucorales. J. Clin. Microbiol. 50:66-75.

Walther, G., Pawłowska, J., Alastruey-Izquierdo, A., Wrzosek, M., RodriguezTudela, J. L., Dolatabadi, S., Chakrabarti, A., and de Hoog, G. S. 2013. DNA barcoding in Mucorales: An inventory of biodiversity. Persoonia 30:11-47.

Webber, H. J., Barker, R., and Ferguson, L. 2014. History and development of the California citrus industry. Pages 3-20 in: Citrus Production Manual. L. Ferguson and E. E. Grafton-Cardwell, eds. University of California Agriculture and Natural Resources Publication 3539, Oakland.

White, T. J., Bruns, T., Lee, S., and Taylor, J. 1990. Amplification and direct sequencing of fungal ribosomal RNA genes for phylogetetics. Pages 315-322 in: PCR Protocols: A Guide to Methods and Applications. M. A. Inis, D. H. Gelfand, J. J. Sninsky, and T. J. White, eds. Academic Press, New York.

Xiao, C. L., and Sitton, J. W. 2004. Effects of culture media and environmental factors on mycelial growth and pycnidial production of Potebniamyces pyri. Mycol. Res. 108:926-932. 